\title{
Bambuseae (Poaceae, Bambusoideae) no município de Viçosa, Minas Gerais, Brasil
}

\author{
Daniele de Freitas Parma ${ }^{1,2}$, Ronaldo Vinícius-Silva ${ }^{1}$, Evandro Pianissola Machado ${ }^{1}$ e \\ Ana Paula Santos-Gonçalves ${ }^{1}$
}

Recebido: 2.02.2016; aceito: 5.07.2016

\begin{abstract}
Bambuseae (Poaceae, Bambusoideae) in the Municipality of Viçosa, Minas Gerais State, Brazil). This study is a floristic survey of the woody bamboos (Poaceae: Bambusoideae: Bambuseae) in Viçosa, Zona da Mata Mineira. Field research was conducted from February/2011 to March/2015. Nine taxa were recognized belonging to two genera Chusquea (two spp.) and Merostachys (seven spp.). Identification keys, descriptions and comments on the studied taxa are provided and the conservation status of each species is examined. Merostachys skvortzovii is recorded for Minas Gerais State for the first time. Merostachys tatianae, previously considered endemic to Parque Estadual do Rio Doce, is here recorded for another locality in Minas Gerais State. This study recorded a high diversity of Bambuseae in the studied area.

Keywords: bamboo, floristics, Semideciduous Forest, taboca, taquara
\end{abstract}

RESUMO - (Bambuseae (Poaceae, Bambusoideae) no Município de Viçosa, MG, Brasil). O presente estudo consiste em um levantamento florístico dos bambus lenhosos (Poaceae: Bambusoideae: Bambuseae) ocorrentes no Município de Viçosa, Zona da Mata mineira. Foram realizadas expedições a fragmentos florestais no Município, no período de fevereiro/2011 a março/2015. São reconhecidos nove táxons pertencentes a dois gêneros Chusquea (duas spp.) e Merostachys (sete spp.). São apresentadas chaves de identificação, descrições, comentários sobre os táxons levantados e o estado de conservação de cada espécie é examinado. É registrada, pela primeira vez, a ocorrência de Merostachys skvortzovii para o Estado de Minas Gerais. Merostachys tatianae, espécie até agora considerada endêmica para o Parque Estadual do Rio Doce, é registrada como ocorrente em outra localidade no Estado. O presente estudo evidencia uma alta diversidade de espécies de Bambuseae na área estudada.

Palavras-chave: bambu, florística, Floresta Estacional Semidecidual, taboca, taquara

\section{Introdução}

As Poaceae Barnhart são plantas de grande importância econômica, ecológica e cultural. A família compreende 12 subfamílias (GPWG 2001), dentre elas Bambusoideae Luerss. que reúne três clados, correspondendo às tribos Olyreae (bambus herbáceos), Bambuseae (bambus lenhosos de clima tropical) e Arundinarieae (bambus lenhosos de clima temperado) (Sungkaew et al. 2009). A subfamília é caracterizada por apresentar plantas em geral rizomatosas, com caules aéreos do tipo colmo, sólidos ou ocos, herbáceos ou lignificados, lâminas foliares pseudopecioladas (Zhang \& Clark 2000). Além disso, apresenta como sinapomorfia a presença de células braciformes e assimétricas, invaginantes no mesofilo das folhas (Zhang \& Clark 2000). Está representada no
Brasil por 50 gêneros e 287 espécies (Flora do Brasil 2016).

A tribo Bambuseae inclui algumas das gramíneas mais complexas do ponto de vista morfológico (Soderstrom et al. 1988). As espécies dessa tribo apresentam folhas do colmo geralmente bem desenvolvidas com bainhas expandidas e lâminas bem desenvolvidas a reduzidas, por vezes, fracamente diferenciadas das folhas dos ramos (BPG 2012). Ocorrem, também, folhas dos ramos com lígula externa, bainhas frequentemente com fímbrias e ramos com desenvolvimento acrópeto ou bidirecional, sendo esta última característica considerada uma sinapomorfia morfológica (BPG 2012).

Os bambus lenhosos, de um modo geral, apresentam ciclo de vida longo e padrão de

1. Universidade Federal de Viçosa, Departamento de Biologia Vegetal, Av. Purdue s/n., 36570-900 Viçosa, Minas Gerais, Brasil

2. Autor para correspondência: danielefparma@gmail.com 
floração cíclica, no qual as plantas crescem vegetativamente por um número determinado de anos, que é característico para cada espécie, e, ao atingir a maturidade fisiológica, florescem, produzem sementes e morrem (Seifriz 1950, Janzen 1976, Soderstrom 1981) abrindo clareiras na mata, o que permite a colonização do estrato inferior da mata por espécies pioneiras.

Embora já existam alguns registros de levantamentos de gramíneas para o Estado de Minas Gerais, poucos são os que abordam especificamente os bambus, sendo os de Santos-Gonçalves et al. (2006), Ferreira et al. (2009), Vinícius-Silva (2015) e Silva (2016) os mais recentes e relevantes. Portanto, o Estado ainda carece de pesquisas dirigidas a este grupo tão diverso.

Diante do exposto, o presente estudo objetivou: 1. Levantar as espécies de Bambuseae ocorrentes no Município de Viçosa; 2. elaborar chave de identificação para as espécies catalogadas; 3 . fornecer descrições, ampliando assim o conhecimento sobre a morfologia, taxonomia e distribuição dos bambus lenhosos ocorrentes na região.

\section{Material e métodos}

O município de Viçosa está localizado no Estado de Minas Gerais, Sudeste do Brasil (20 45'23"S e $\left.42^{\circ} 52^{\prime} 23^{\prime \prime} \mathrm{W}\right)$, e apresenta aproximadamente $25 \%\left(74,849 \mathrm{~km}^{2}\right)$ do seu território composto por fragmentos de Floresta Atlântica (Coelho et al. 2005). O clima da região, segundo a classificação de Köppen, é Cwa, mesotérmico úmido, com verões chuvosos e invernos secos (Silva et al. 2003). A precipitação pluvial média anual é de $1.248 \mathrm{~mm}$, a umidade anual relativa do ar de $80,6 \%$ e a temperatura média anual é de $21^{\circ} \mathrm{C}$ (Silva et al. 2003).

A vegetação predominante nos fragmentos florestais da região é a de Floresta Estacional Semidecídua Montana (Veloso et al. 1991). A altitude média da região é de $670 \mathrm{~m}$, com relevo variando de ondulado a montanhoso (Silva et al. 2003).

As expedições a campo foram realizadas mensalmente (total de 49) entre fevereiro de 2011 e março de 2015 e conduzidas por meio de uma adaptação ao método do caminhamento descrito por Filgueiras et al. (1994). As coletas foram concentradas nos fragmentos florestais Estação de Pesquisa, Treinamento e Educação Ambiental (EPTEA) $\left(20^{\circ} 45^{\prime} \mathrm{S}\right.$ e $\left.42^{\circ} 55^{\prime} \mathrm{W}\right)$, Fazenda Bom Sucesso (Mata do Sr. Nico) $\left(20^{\circ} 47.801^{\prime} \mathrm{S}\right.$ e $\left.42^{\circ} 50.725^{\prime} \mathrm{W}\right)$ e Mata da Biologia $\left(20^{\circ} 45.384^{\prime} \mathrm{S}\right.$ e $\left.42^{\circ} 52.365^{\prime} \mathrm{W}\right)$. Foram também contabilizadas neste estudo espécies: 1 . registradas como ocorrentes no município de Viçosa no herbário VIC; 2. registradas como ocorrentes no município de Viçosa nos herbários: CRI, CVRD, ESA, FLOR, FURB, G, HAS, HB, HCF, HRB, HRCB, IAC, ICN, INPA, ISC, K, MBML, MO, MPUC, NY, OUPR, P, PAMG, PMSP, RB, SP, SPF, SPSF, UB, UEC e US (acrônimos de acordo com Thiers 2016).

Os materiais foram coletados de acordo com as recomendações de Soderstrom \& Young (1983) e herborizados segundo os métodos tradicionalmente adotados em taxonomia de angiospermas. Posteriormente, os espécimes foram incorporados ao acervo do herbário da Universidade Federal de Viçosa (VIC) e as duplicatas serão enviadas aos herbários OUPR, SP e K.

Os espécimes coletados foram identificados por meio de literatura especializada, consulta a especialistas e comparação com materiais tipo e fotos provenientes dos herbários BHCB, HRCB, ICN, ISC, MO, RB, UB, UEC, US e VIC. As espécies foram descritas segundo a terminologia morfológica proposta por McClure (1966) e Radford et al. (1974) e tendo como referência os materiais examinados da área estudada. As análises morfológicas foram conduzidas com auxilio de uma lupa estereomicroscópica e as medidas das estruturas, vegetativas e reprodutivas, foram realizadas com auxílio de paquímetro, régua e papel milimetrado.

\section{Resultados e Discussão}

Durante esse estudo foram analisados, aproximadamente, 62 exsicatas e coletados 25 indivíduos, sendo cinco férteis e o restante em estádio vegetativo. Os táxons estão taxonomicamente posicionados em duas subtribos neotropicais (Arthrostylidiinae e Chusqueinae), incluídos em dois gêneros (Chusquea Kunth e Merostachys Spreng.), totalizando nove espécies. Ressalta-se que o número de espécies levantadas no Município é alto quando comparado com inventários realizados em outras localidades do Estado de Minas Gerais (Viana 2005, Santos-Gonçalves et al. 2006, Ferreira et al. 2009, Silva 2016) (tabela 1). Ademais, é importante salientar que não observamos nenhum bambu herbáceo (Olyreae) nas áreas estudadas. 
Chave de identificação para as espécies de Bambuseae ocorrentes no município de Viçosa

1. Entrenó sólido, complemento de ramo com um ramo dominante e ramos subsidiários subiguais

2. Folha do colmo com bainha escabra, lâmina ereta, não pseudopeciolada, persistente; ramificação infravaginal; lígula interna da folha dos ramos $0,8-1,4 \mathrm{~mm}$ de compr. Chusquea urelytra

2. Lâmina da folha do colmo reflexa, pseudopeciolada, decídua; ramificação extravaginal; lígula interna da folha dos ramos 6-25 $\mathrm{mm}$ de compr. Chusquea tenuiglumis

1. Entrenó fistuloso, complemento de ramos com ramificação apsidada e ramos subiguais

3. Entrenó com tricomas híspidos e urentes Merostachys tatianae

3. Entrenó glabro, pubescente, escabro ou com tricomas lanosos

4. Nós do colmo e do complemento de ramos proeminentes, em formato anelar ...Merostachys sp. morfoespécie 1 4. Nós do colmo e do complemento de ramos não proeminente, sem formato anelar

5. Entrenó do mediocolmo levemente triangular e bainha da folha dos ramos com tricomas híspidos ..... Merostachys sp. morfoespécie 2

5. Entrenó do mediocolmo cilíndrico e bainha da folha dos ramos glabra

6. Faixa infranodal de tricomas velutinos ausente Merostachys sp. morfoespécie 3

6. Faixa infranodal de tricomas velutinos presente

7. Entrenó escabro, verde com estrias amarelas Merostachys skvortzovii

7. Entrenó glabro, verde-amarelado sem estrias

8. Ramos do complemento de ramos com 0,9-1,2 mm diâmetro; espiguetas 6-9 mm de compr., glumas I e II mucronadas Merostachys fischeriana

8. Ramos do complemento de ramos com 1,5-1,9 mm diâmetro; espiguetas 12-17 mm de compr., glumas I e II aristadas Merostachys claussenii var. claussenii

1. Chusquea urelytra Hack. Oesterr. Bot. Z. 53: 158. 1903.

Figuras 1a, 2a

Planta com colmo inicialmente ereto e posteriormente apoiante sobre a vegetação, $8-10 \mathrm{~m}$ de compr. Entrenó 11-23 cm compr., verde claro, pubescentes a escabros, 0,9-1,3 cm de diâmetro. Linha nodal assimétrica, com tricomas esparsos, castanho-vinácea, região nodal $5 \mathrm{~mm}$ de largura, glabra, verde-clara; anel supranodal conspícuo, verde-vináceo, ramificação infravaginal. Folhas do colmo persistentes, não pseudopecioladas, com pouca distinção entre lâmina e bainha, ultrapassando ou não o próximo nó; bainha 12,8-22,3 × 2,0-2,7 cm, não aderente, face abaxial escabrosa, castanha, com pontuações escuras, face adaxial glabra, castanhobrilhante, margem pilosa. Complemento de ramo 9-14 ramos subsidiários subiguais, nós basais geniculados, dispostos em 1-2 fileiras curvas ao redor do ramo central, conferindo aspecto aracnoide, alguns com ramificação secundária, estes com 11-32 cm compr. Folhas dos ramos 2-3 por ramo; 2-6 nós por ramo; bainha 2,2-3,0 × 2,0-2,7 cm, face abaxial densamente pilosa, escabrosa, castanha, com pontuações escuras, face adaxial glabra, castanho-brilhante, margem pilosa; lígula externa glabra ou uma faixa de tricomas; lígula interna 0,8-1,4 mm compr., assimétrica, truncada, membranosa, margem inteira, verde, glabra; pseudopecíolo 1-2 mm compr., glabros a híspidos em ambas as faces; lâminas 8-20,1 × 1,4-2,9 cm, lanceoladas, glabras em ambas as faces ou face abaxial pilosa, às vezes com um tufo de tricomas na base da face abaxial. Inflorescência panícula, 1-3 cm compr., capitada, terminal. Espiguetas 6-8 mm compr.; gluma I 2-4 mm compr., 1-3 nervada, aristada, arista 1-1,8 mm, pilosa; gluma II 2-4 mm compr., 3-5 nervada, aristada, arista 1-1,8 mm de compr., pilosa; gluma III 4,8-6 mm compr., 5-7 nervado, aristada, arista $1 \mathrm{~mm}$ compr., piloso; gluma IV 6-8 mm compr., 7-nervada, mucronada, glabro a metade superior pilosa; lema 6,2-7,3 mm compr., 7 nervado, apiculado, glabro a metade superior piloso; pálea 6,4-8 $\mathrm{mm}$ compr., 6 nervada, híspida; lodículas 3, com 1,5-1,7 mm compr., lanceoladas, ápice ciliado; anteras não vista. Gineceu com 2 estigmas. Cariopse não vista.

Material examinado: BRASIL. MinAs GeRAIS: Viçosa, Fazenda Bom Sucesso, Mata do Sr. Nico, 12-IX-2014, D.F. Parma \& C.A. Costa 41, veg., (VIC). Idem, 12-IX-2014, D.F. Parma \& C.A. Costa 46, veg., (VIC). Idem, 12-IX-2014, D.F. Parma \& C.A. Costa 47, fl., (VIC). Idem, 10-X-2014, D.F. Parma \& C.A. Costa 50, veg., (VIC). Idem, 10-X-2014, D.F. Parma \& C.A. Costa 59, fl., (VIC). Estação de Pesquisa, Treinamento e Educação Ambiental (EPTEA), Mata 
do Paraíso, Trilha do pesquisador, 18-III-2015, R.V. Silva \& D.F. Parma 58, fl., (VIC). ESAV, 1935, J.J. Kuhlman s.n., fl., (VIC).

Material adicional: BRASIL. Minas Gerais: Araponga, Parque Estadual da Serra do Brigadeiro, Trilha do Panelão dos Muriquis, 21-X-2013, E.M. Pianissola, A.L. Fontes \& M.N. Moura 5, veg., (VIC). Idem, 21-X-2013, E.M. Pianissola, A.L. Fontes \& M.N. Moura 6, veg., (VIC). Trilha do Pai Inácio, 17-VI-2015, A.P. Silva \& J. Carrión 204, veg., (VIC).

Chusquea urelytra distingue-se das demais espécies do gênero ocorrentes em Viçosa por apresentar folha do colmo com bainha escabra, lâmina ereta, não pseudopeciolada, persistente, ramificação infravaginal e lígula interna da folha dos ramos com 0,8-1,4 mm de compr.

Distribuição: Chusquea urelytra ocorre do Sudeste de Minas Gerais até Santa Catarina em áreas caracterizadas por Veloso et al. (1991) como Floresta Atlântica Estacional Semidecidual Montana e Floresta Atlântica Estacional Semidecidual Submontana. De acordo com Shirasuna et al. (2015), C. urelytra apresenta distribuição nas regiões Sudeste (ES, RJ e SP), Nordeste (BA) e Sul (SC, PR). Judziewicz et al. (1999), Mota (2013) e Silva (2016) citam a espécie, também, para o Estado de Minas Gerais.

Conservação: de acordo com os critérios utilizados pelo CNCFLORA, a espécie se encontra na categoria menos preocupante, por ser abundante e amplamente distribuída.

2. Chusquea tenuiglumis Döll. Fl. Bras. (Martius) 2(3): 199. 1880.

Figuras $1 b, 2 b$

Planta com colmos inicialmente eretos e posteriormente inclinando-se sobre a vegetação, 2-8 m compr. Entrenó 30-33 cm compr., verde-amarelado, glabro, 0,9-1 cm de diâmetro. Linha nodal linear, com tricomas esparsos, castanho-vinácea, região nodal $3 \mathrm{~mm}$ de largura, glabra, verde-clara; anel supranodal conspícuo, verde-vináceo, ramificação infravaginal. Folhas do colmo persistentes, pseudopecioladas; bainha 11,7-27,0 × 2,1-3,4 cm, face abaxial com tricomas esparsos, castanha, face adaxial glabra, castanho-brilhante; lâmina 1,9-7,1 cm compr., reflexa, face abaxial com tricomas estrigosos, castanha, com pontuações escuras; face adaxial glabra, castanho-brilhante. Complemento de ramo com 5-9 ramos subsidiários subiguais, nós basais geniculados, dispostos em 1-2 fileiras curvas ao redor do ramo central, dando aspecto aracnoide, estes com $32-62 \mathrm{~cm}$ compr. Folhas dos ramos pseudopecioladas verdes 3-6 por ramo; 3-8 nós por ramo; bainha $12,8-22,3 \times 2-2,7 \mathrm{~cm}$, não aderentes, face abaxial escabrosa, castanha, com pontuações escuras, face adaxial glabra, castanho-brilhante, margem pilosa; lígula externa glabra ou uma faixa de tricomas; lígula interna 0,6-1,2 mm compr., assimétrica, truncada, membranosa, margem inteira, verde, glabra; pseudopecíolo 1-2 mm compr., glabros a híspidos em ambos os lados; lâminas 7-13,1 × 1,4-1,8 cm, lanceoladas, glabras em ambas as faces ou face abaxial hirsuta, às vezes com um tufo de tricomas na base da face abaxial. Inflorescência não vista.

Material examinado: BRASIL. MinAS GERAIS: Viçosa, Universidade Federal de Viçosa, 19-I-2015 E.M. Pianissola 69, veg., (VIC).

Material adicional: BRASIL. Minas Gerais: Araponga, Parque Estadual da Serra do Brigadeiro, Trilha Matipó, 16-IV-2015, A.P. Silva \& E.P. Machado 167, veg., (VIC).

Chusquea tenuiglumis distingue-se das demais espécies do gênero ocorrentes em Viçosa por apresentar

Tabela 1. Comparação entre o número de espécies de Bambuseae encontradas no município de Viçosa com outras localidades em Minas Gerais.

Table 1. Comparison of the number of species of Bambuseae collected in Viçosa with other localities in Minas Gerais.

\begin{tabular}{lccccc}
\hline Localidade & $\begin{array}{c}\text { Espécies de } \\
\text { Bambuseae }\end{array}$ & $\begin{array}{c}\text { Área total } \\
\left(\mathrm{km}^{2}\right)\end{array}$ & $\begin{array}{c}\text { Área }\left(\mathrm{km}^{2}\right) \text { por Espécie por área } \\
\text { espécie }\end{array}$ & \multirow{2}{*}{ Referência } \\
\hline Viçosa & 9 & 74,85 & 8,32 & 0,120 & Presente estudo \\
Parque Estadual do Ibitipoca & 10 & 14,88 & 1,48 & 0,672 & Ferreira et al. (2009) \\
Parque Estadual da Serra do Brigadeiro & 25 & 149,84 & 5,99 & 0,167 & $\begin{array}{c}\text { Silva (2016) } \\
\text { Parque Estadual do Rio Doce }\end{array}$ \\
Parque Estadual do Rio Preto & 9 & 359,70 & 39,97 & 0,25 & $\begin{array}{c}\text { Santos-Gonçalves } \\
(2006)\end{array}$ \\
\hline
\end{tabular}




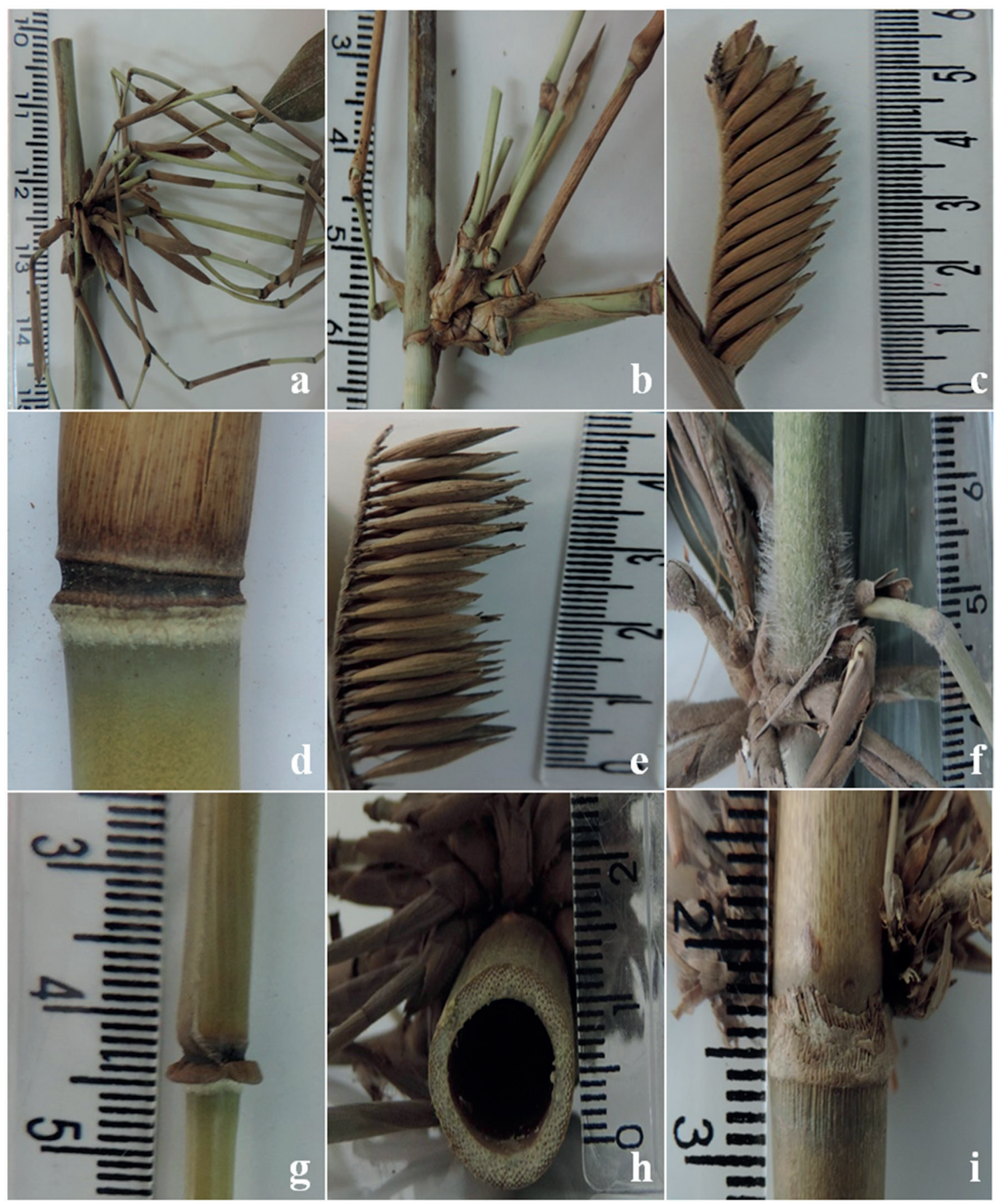

Figura 1. a. Chusquea urelytra (Parma \& Celso 47): ramificação infravaginal no complemento de ramo. b. Chusquea tenuiglumis (Pianissola 69): ramificação extravaginal no complemento de ramo. c. Merostachys claussenii var. claussenii (VIC1234): inflorescência. d. Merostachys fischeriana (Parma \& Costa 48): faixa infranodal de tricomas velutinos presentes. e. Merostachys skvortzovii (Miranda s.n. 2014): inflorescência. f. Merostachys tatianae. (Parma \& Celso 40): entrenó com tricomas urentes. g. Merostachys sp. morfoespécie 1 (Silva \& Parma 56): nós do complemento de ramo proeminentes. h. Merostachys sp. morfoespécie 2 (Paz 4): formato do entrenó subtriangular. i. Merostachys sp. morfoespécie 3 (Mexia 4578): faixa infranodal de tricomas velutinos ausente.

Figure 1. a. Chusquea urelytra (Parma \& Celso 47): infravaginal branch on the branch complement. b. Chusquea tenuiglumis (Pianissola 69): extravaginal branch on the branch complement. c. Merostachys claussenii var. claussenii (VIC1234): inflorescence. d. Merostachys fischeriana (Parma \& Costa 48): infranodal band of velutinous trichomes. e. Merostachys skvortzovii (Miranda s.n. 2014): inflorescence. f. Merostachys tatianae. (Parma \& Celso 40): internode with stinging trichomes. g. Merostachys sp. morphospecie 1 (Silva \& Parma 56): branch complement nodes prominent. h. Merostachys sp. morphospecie 2 (Paz 4): subtriangular culm. i. Merostachys sp. morphospecie 3 (Mexia 4578): infranodal band of velutinous trichomes absent. 
lâmina da folha do colmo reflexa, pseudopeciolada, decídua, ramificação extravaginal e lígula interna da folha dos ramos com 6-25 mm de compr.

Distribuição: de acordo com Shirasuna et al. (2015), C. tenuiglumis ocorre nas regiões Sudeste (MG, SP) e Sul do país (SC), sendo comum em regiões caracterizada por Veloso et al. (1991) como Floresta Atlântica Estacional Semidecidual Montana.

Conservação: Chusquea tenuiglumis tem registro de ocorrência em áreas de Mata Atlântica que apresentam mais de $80 \%$ de sua cobertura original degradada, como os Municípios de Baependi, Camanducaia, Poços de Caldas e Salto da Divisa (MG). Dessa forma, as subpopulações da espécie sofreram uma redução drástica, sendo considerada em "Criticamente em perigo" (CR) (CNCFLORA). Entretanto, $C$. tenuigluimis foi citada, também, para o Parque Estadual da Serra do Brigadeiro (Silva 2016). Logo, consideramos a espécie como vúlnerável de acordo com os critérios do CNFLORA.

\section{Merostachys claussenii var. claussenii Munro.}

Trans. Linn. Soc. London 26(1): 48. 1868.

Figuras 1c, 2c

Planta com hábito desconhecido. Entrenó incompleto, cilíndrico, 0,8-2,2 cm de diâmetro, parede com 1,7-3,3 mm de espessura, verde-amarelado sem estria, brilhante, glabro, faixa infra e supranodal com tricomas velutinos 1-5,7 mm compr.; região mediana cilíndrica. Nó não proeminente, castanho. Folha do colmo não vista. Complemento de ramo com ca. 50 ramos, estes com 15-33 cm compr., 1,5-1,9 de diâmetro, ramos de segunda ordem ausentes; nós não proeminentes, castanhos. Folha dos ramos 4-7 por ramo; bainha $1,5-9,7 \mathrm{~cm} \times 2,1-5,4 \mathrm{~mm}$, glabra a pubescente, margem sobreposta ciliada; aurículas ausentes; lígula externa 0,1-0,2 mm compr., ápice ciliado; lígula interna 0,3-1,2 mm compr., membranácea, pubescente, ápice ciliado; fímbrias não fusionadas, 0,7-7,8 mm compr., retas a sinuosas, amareladas a castanhas; pseudopecíolo 1,56-3,85 mm compr., castanho, retorcido, seríceo a híspido; lâmina 4-11,5 × 1,3-2,9 cm, lanceolada a oval lanceolada, base assimétrica, ápice acuminado, margens escabras, face adaxial frequentemente com 3-4 nervuras marginais escabras, base pubescente, glabro no restante, face abaxial glabra a pubescente com um tufo de tricomas híspidos na base, ápice escabro. Inflorescência racemosa, pectinada, 3,3-9,5 cm compr., raque tomentosa, bráctea estéril na base do racemo ausente, 11-38 espiguetas, espiguetas rudimentares no ápice e, às vezes, na base. Espiguetas 12-17 × 1,5-3 mm, solitárias, 1-flora, pedicelo 1-1,5 mm compr., tomentoso. Glumas 2, desiguais. Gluma I 2,5-5 × 1-2 mm, aristada, arista 0,5-1,5 mm compr., 1-4-nervada, serícea, margens ciliadas. Gluma II $12.5-16 \times 3.5-5 \mathrm{~mm}$, aristada, arista $1-1,7 \mathrm{~mm}$ compr., 12-15-nervada, híspida próximo às nervuras, serícea no restante, margens apicais ciliadas, uma das margens ciliada desde a base. Lema 12-14 × 4-6.5 mm, 14-19-nervado, seríceo, margens apicais ciliadas, uma das margens ciliada até próximo à base. Pálea 11-14 × 3-5 mm, 6-10-nervada, pubérula, margens apicais ciliadas, nervuras centrais constituindo quilha, quilha ciliada. Extensão da ráquila 10,5-12,8 mm compr. Cariopse não vista.

Material examinado: BRASIL. Minas Gerais: Viçosa, Universidade Federal de Viçosa, 13-XII-1934, A. Chase, fl., (VIC1234).

Material adicional: BRASIL. RIO DE JANEIRO: próximo ao Rio de Janeiro, Serra dos Órgãos, 1838-1842, Wilkes s.n., fl., (Síntipo: K foto NY foto fragmento US). Idem, s.d., Miers 4238, fl., (Síntipo: P foto K foto). Sem localidade 1842, P. Claussen s.n., fl., (Síntipo: G foto Fragmento US).

Merostachys claussenii Munro var. claussenii distingue-se das demais espécies do gênero ocorrentes em Viçosa por apresentar colmo brilhante, espiguetas com 8-11 mm compr. e gluma I 1-4 nervada.

Lizarazu et al. (2011) sinonimizaram as duas variedades de $M$. claussenii (M. claussenii var. claussenii e $M$. claussenii var. mollior) juntamente com M. burchelli Munro como Merostachys claussenii Munro. Entretanto, Vinícius-Silva (2015), após analisar o material tipo dessas duas variedades nos herbários K e US, verificou diferenças consideráveis nas estruturas reprodutivas entre elas. Assim, diante dessas informações, consideramos, neste estudo, M. claussenii var. claussenii um táxon distinto de M. claussenii var. mollior, conforme sugerido por Vinícius-Silva (2015).

Distribuição: Merostachys claussenii no Brasil ocorre na região Sudeste (Judziewicz et al. 1999) e Sul (Schimdt \& Longhi-Wagner 2009), no Paraguai ao Leste e na Argentina ao Nordeste (Judziewicz et al. 1999). Entretanto, Vinícius-Silva (2015) em seu trabalho considerou uma distribuição semelhante àquela citada na obra original, com registros para o Rio de Janeiro e Minas Gerais, sendo comum em regiões 

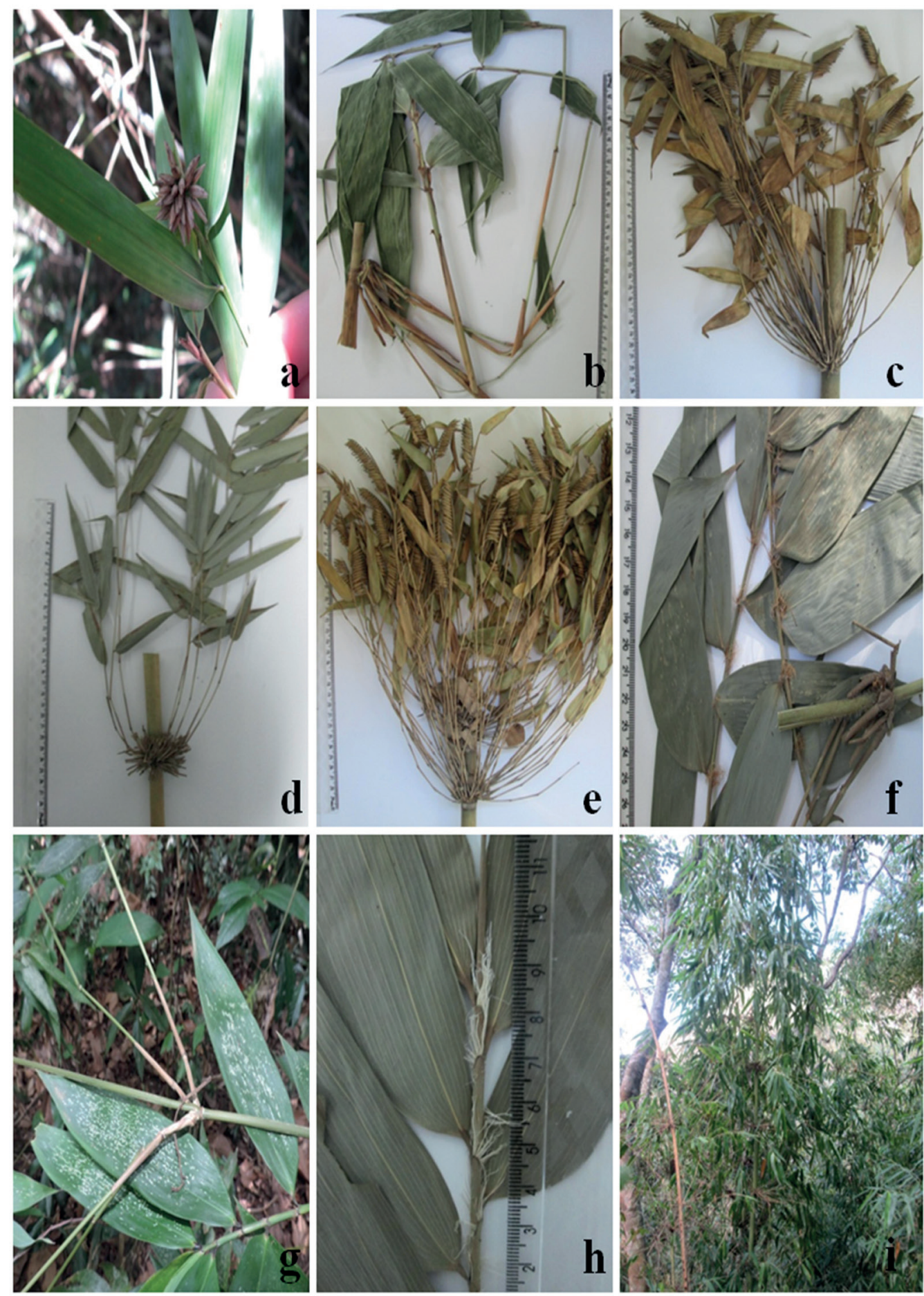

Figura 2. a.Chusquea urelytra inflorescência. b. Chusquea tenuiglumis (Pianissola 69): complemento de ramo. c. Merostachys claussenii var. claussenii (VIC1234): complemento de ramo. d. Merostachys fischeriana (Silva \& Parma 59): complemento de ramo. e. Merostachys skvortzovii (Miranda s.n. 2014): complemento de ramo com inflorescência. f. Merostachys tatianae (Silva \& Parma 57): complemento de ramo e fímbrias amareladas. g. Merostachys sp. morfoespécie 1 (Silva \& Parma 56): complemento de ramo. h. Merostachys sp. morfoespécie 2 ( $\mathrm{Paz}$ 6): fímbrias prateadas em direção ao ápice. i. Merostachys sp. morfoespécie 3 hábito.

Figure 2. a. Chusquea urelytra inflorescence. b. Chusquea tenuiglumis (Pianissola 69): branch complement. c. Merostachys claussenii var. claussenii (VIC1234): branch complement. d. Merostachys fischeriana (Silva \& Parma 59): branch complement. e. Merostachys skvortzovii (Miranda s.n. 2014): branch complement with inflorescence. f. Merostachys tatianae (Silva \& Parma 57): branch complement and yellow fimbriae. g. Merostachys sp. morphospecie 1 (Silva \& Parma 56): branch complement. h. Merostachys sp. morphospecie 2 (Paz 6): fimbriae silver towards the apex. i. Merostachys sp. morphospecie 3 habit. 
caracterizada por Veloso et al. (1991) como Floresta Atlântica Estacional Semidecidual Montana.

Conservação: de acordo com os critérios utilizados pelo CNCFLORA, o táxon se encontra na categoria dados insuficientes, pois o que temos são poucos registros, de coletas antigas.

4. Merostachys fischeriana Rupr. ex Döll. Fl. Bras. (Martius) 2 (3): 215. 1880.

Figuras 1d, 2d

Planta com colmos inicialmente eretos e posteriormente inclinando-se sobre a vegetação, 10-12 m de comp. Entrenó 36-52 cm comp., verde-amarelado sem estria, brilhante, glabro na maturidade, 0,3-1,2 $\mathrm{cm}$ de diâmetro, parede com 1-3,2 mm de espessura, faixa infranodal de tricomas, 1-6 mm; região mediana cilíndrica. Nó não proeminente, castanho. Folha do colmo com bainha 21,4-32 × 4,4-6,7 cm, face adaxial glabra, face abaxial glabra; fímbrias 5-7 mm, eretas a sinuosas, enroladas no ápice, amareladas a avermelhadas; lígula interna 0,2-0,4 mm. Complemento de ramo com 34-53 ramos, estes com 13-33 cm comp., 0,9-1,2 de diâmetro ramos de segunda ordem ausentes. Folhas dos ramos verdes 6-8 por ramo; bainha 3-4 $\mathrm{cm} \times 2,8-3,6 \mathrm{~mm}$, glabra ou esparsamente hirsuta, margem sobreposta ciliada; fímbrias 1-2,6 mm; retas a sinuosas, geralmente enroladas no ápice, amareladas a avermelhadas; lígula externa $0,1-0,3 \mathrm{~mm}$ compr.; lígula interna 0,3-0,5 mm compr.; pseudopecíolo 3-4,6 mm, esverdeado a castanho, pubescente a tomentoso; lâmina 8-12,8 × 0,8-1,4 cm, lanceolada, base simétrica a assimétrica, ápice acuminado, margens serreadas, face adaxial glabra e face abaxial com uma fileira de tricomas próximo à margem. Inflorescência racemosa, pectinada, 3,16-7,69 cm compr., raque velutina, bráctea estéril na base do racemo ausente, 23-55 espiguetas, espiguetas rudimentares no ápice e, por vezes, na base. Espiguetas 6-9 × 1-3 mm, solitárias, 1-flora, pedicelo 0,5-1 mm compr., velutino a tomentoso. Glumas 2, desiguais. Gluma I 1-2,8 × 0,3-1 mm, 1-nervada, glabra a pubescente, nervura central escabra, margens ciliadas, por vezes com manchas escuras adaxialmente. Gluma II 3-6 x 1,5-2,5 mm, mucronada, 5-10-nervada, glabra a pubescente, nervura central escabra, margens apicais ciliadas, manchas escuras adaxialmente. Lema 5-8 × 2,5-4 mm, 9-13-nervado, glabro a pubescente, margens apicais ciliadas, manchas escuras adaxialmente. Pálea 5-8,3 × 2-4 mm, 6-9-nervada, glabra a pubescente no ápice, margens apicais ciliadas, nervuras centrais constituindo quilha, quilha ciliada em direção ao ápice. Extensão da ráquila 3,5-7,5 mm compr. Cariopse não vista.

Material examinado: BRASIL. MinAs GerAis: Viçosa, Fazenda Bom Sucesso, Mata do Sr. Nico, 12-IX-2014, D.F. Parma \& C.A. Costa 48, veg., (VIC). Idem, 10-X-2014, D.F. Parma \& C.A. Costa 53, veg., (VIC). 10-X-2014. Idem, D.F. Parma \& C.A. Costa 54, veg., (VIC). Estação de Pesquisa, Treinamento e Educação Ambiental (EPTEA), Mata do Paraíso, Trilha do pesquisador, 18-III-2015, R.V. Silva \& D.F. Parma 59, veg., (VIC). Sem localidade, 6-XI-1930, Y. Mexia 4578, fl., (VIC).

Material adicional: BRASIL. Minas Gerais: Brás Pires, Rodovia Senador Firmino-Brás Pires, MG-124, 9-III-2014, R.V. Silva \& E.A. Silva 12, veg., (VIC). Carrancas, Serra dos Perdizes, 2-XII-2007, P.L. Viana, F.S.F. Leite \& C.G. Leal 3325, fl., (BHCB). Jaboticatubas, Km 126 ao longo da rodovia Lagoa Santa, Conceição do Mato Dentro, Diamantina, 7-IV-1974, J. Semir \& M. Sazima 4977, fl., (UEC).

Merostachys fischeriana distingue-se das demais espécies do gênero ocorrentes em Viçosa por apresentar uma faixa infranodal de tricomas velutinos e colmo verde-amarelado, brilhante.

Distribuição: a espécie foi registrada para os Estados brasileiros de Minas Gerais (Judiziewicz et al. 1999), Bahia, Rio de Janeiro (Renvoize 1984), Espírito Santo e Paraná (Shirasuna 2015). Em Minas Gerais é amplamente distribuída, sendo comum em regiões que apresentam sub-bosque e em borda de vegetação caracterizada por Veloso et al. (1991) como Floresta Atlântica Estacional Semidecidual Montana.

Conservação: de acordo com os critérios utilizados pelo CNCFLORA, a espécie se encontra na categoria menos preocupante, por ser abundante e amplamente distribuída.

5. Merostachys skvortzovii Send. Novon 5: 94. 1995. Figuras 1e, 2e

Hábito não visto. Entrenó incompleto, verde com estrias amarelas, fosco, coberto por tricomas, $0,6-1 \mathrm{~cm}$ de diâmetro, parede com 1,2-2 mm de espessura, faixa infranodal de tricomas presentes 2-3,5 mm; região mediana cilíndrica. Nó não proeminente, castanho. Folha do colmo não vista. Complemento de ramo com 27-51 ramos, estes com 21-48 cm compr., 0,9-1,2 mm de diâmetro, ramos de segunda ordem ausentes. Folhas dos ramos verdes 7-10 por ramo; 
bainha 5,3-8,4 cm $\times 5-9 \mathrm{~mm}$, glabra ou esparsamente hirsuta, margem sobreposta ciliada; fímbrias 2-8 $\mathrm{mm}$ compr., não fusionadas, retas a onduladas, castanhos; lígula externa 0,12-0,36 mm compr., ápice ciliado; lígula interna 0,1-2,4 mm compr., membranácea, pubescente, ápice ciliado; pseudopecíolo 2,5-3 mm compr., esverdeado a castanho, glabro a puberulento, retorcido; lâmina 7,5-9,5 × 1,2-1,8 cm, lanceolada, face adaxial com 2-3 nervuras marginais escabras, ápice escabro, glabra no restante, face abaxial glabra com um tufo de tricomas híspidos na base, base assimétrica a simétrica, ápice acuminado e margens escabras. Inflorescência racemosa, pectinada, 1,5-5,2 cm compr., pedunculada, raque velutina, bráctea estéril na base do racemo ausente, 24-30 espiguetas, espigueta rudimentar no ápice. Espiguetas 10-11 × 1,8-3 mm, solitárias, 1-flora, pedicelo 1-2 mm compr., velutino. Glumas 2, desiguais. Gluma I ca. $2 \times 1-1,5 \mathrm{~mm}$, 1-nervada, pubescente, margens ciliadas. Gluma II 8,5-9,5 × 3,4-4 mm, mucronada, 10-12 nervada, pubescente, margens ciliadas em direção ao ápice. Lema 9-9,5 × 5-5,5 mm, 12-15 nervado, pubescente, margens apicais ciliadas, uma das margens ciliada desde a base. Pálea 9,5-11 × 3-5 mm, 8-10 nervada, pubérula, margens apicais ciliadas, nervuras centrais constituindo quilha, quilha ciliada em direção ao ápice, manchas escuras adaxialmente. Extensão da ráquila ca. 7,5 mm compr. Lodículas, Androceu e Gineceu não vistos. Cariopse 4,5-6 × ca. $2 \mathrm{~mm}$, oval, rostrada, castanha, hilo visível.

Material examinado: BRASIL. Minas Gerais: Viçosa, Universidade Federal de Viçosa, Zootecnia, 2014, A.A. Miranda, fl., (VIC).

Material adicional: BRASIL. Rio GRANDE Do Sul: Canela, 15-I-2006, C. Welker 142, fl., (ICN). Idem, Derrubadas, Parque Estadual do Turvo, Porto Guarcia. 21-XII-2003, G.A. Bencke \& J.K.F. Mahler Jr., fl., (HAS42609). Paraná, Ponta Grossa, Reserva Natural Buraco do Padre, 23-XI-2005, J.R. Stehmann et al. 4230, fl., (BHCB).

Merostachys skvortzovii distingue-se das demais espécies do gênero ocorrentes em Viçosa por apresentar colmo verde-amarelado fosco, espiguetas com 12-17 mm compr. e gluma I sempre 1- nervada.

Distribuição: Merostachys skvortzovii ocorre no bioma Mata Atlântica, nas regiões Sudeste (SP) e Sul (PR, RS, SC) (Shirasuna 2015). No presente estudo ampliase a área de ocorrência da espécie para o Estado de Minas Gerais.
Conservação: Merostachys skvortzovii ainda não foi avaliada pela Lista Vermelha da IUCN. Embora, no Livro Vermelho das Espécies Vegetais Ameaçadas do Estado de São Paulo (Mamede et al. 2007), esteja inserida na categoria "vulnerável".

6. Merostachys tatianae Santos-Gonç., Carv.-Okano \& Filg. Syst. Bot. 37(4): 938. 2012

Figuras 1f, $2 f$

Planta com colmos inicialmente eretos e posteriormente inclinando-se sobre a vegetação, 10-12 m de comp. Entrenó 20-77 cm comp., verdeamarelado sem estrias, fosco, híspido e urentes, coberto por tricomas, 1,1-2,7 cm de diâmetro, parede com 1-2 mm de espessura, faixa infranodal de tricomas, 1-1,7 mm; região mediana cilíndrica. Nó não proeminente, castanho. Folha do colmo com bainha $30-36,5 \times 10,5-13 \mathrm{~cm}$, face adaxial coberta por tricomas brancos, reluzentes e esparsos, face abaxial coberta por tricomas brancos e base com girdle 0,1-0,4 cm; lígula interna 0,7-1 mm, membranácea; fímbrias 3-5 $\mathrm{mm}$, eretas a sinuosas, enroladas no ápice, amareladas avermelhadas; lâmina 11-22,5 × 2-5,5 mm, margens ciliadas em direção ao ápice, face adaxial glabra, face abaxial coberta com diminutos tricomas estrigosos, às vezes esparsamente hirsuta. Complemento de ramo com 10-12 ramos, estes com 24-78 cm comp., 2,2-5,4 de diâmetro ramos de segunda ordem ausentes. Folhas dos ramos verdes 11-13 por ramo; bainha $6,7-9,5 \mathrm{~cm} \times 17-21 \mathrm{~mm}$, glabra ou esparsamente hirsuta, margem sobreposta ciliada; lígula externa 0,13-0,45 mm compr., ápice ciliado; lígula interna 0,1-2,64 mm compr., membranácea, pubescente, ápice ciliado; pseudopecíolo 6-8,6 mm, esverdeado a castanho. Inflorescência não vista.

Material examinado: BRASIL. Minas Gerais: Viçosa, Fazenda Bom Sucesso, Mata do Sr. Nico, 27-VIII-2014, D.F. Parma \& R.V. Silva 40, veg., (VIC). Idem, 10-X-2014, D.F. Parma \& C.A. Costa 58, veg., (VIC). Estação de Pesquisa, Treinamento e Educação Ambiental (EPTEA), Mata do Paraíso, Trilha do pesquisador, 18-III-2015, R.V. Silva \& D.F. Parma 56, veg., (VIC).

Material adicional: BRASIL. MINAS GERAIS: Marliéria, Parque Estadual do Rio Doce, trilha do Anibal, 23-VII-1999, Santos-Gonçalves et al. 191, veg., holótipo (VIC). Estrada Cava Grande- Ponte Queimada, 21-XII-1999, Santos-Gonçalves et al. 319, veg., (VIC). Idem, 17-IX-1975, E.P. Heringer \& G. Eiten 15017, veg., (VIC). 
Merostachys tatianae distingue-se das demais espécies do gênero ocorrentes em Viçosa por apresentar entrenó com tricomas híspidos e urentes.

Distribuição: a espécie é registrada apenas no Sudeste de Minas Gerais, onde ocorre em sub-bosque e borda de vegetação caracterizada por Veloso et al. (1991) como Floresta Atlântica Estacional Semidecidual Montana e Floresta Atlântica Estacional Semidecidual Submontana. Anteriormente, era conhecida somente no Parque Estadual do Rio Doce (PERD). Neste trabalho amplia-se a área de ocorrência de Merostachys tatianae.

Conservação: de acordo com os critérios utilizados pelo CNCFLORA, o táxon se encontra na categoria dados insuficientes, pois a espécie é registrada somente para o PERD e a área em estudo.

\section{Merostachys sp. morfoespécie 1}

Figuras 1g, $2 \mathrm{~g}$

Planta com colmos inicialmente eretos e posteriormente inclinando-se sobre a vegetação, 2-12 m de compr. Entrenó 16-32 cm compr., verdeamarelado sem estrias, fosco, coberto por tricomas lanosos, 0,5-1,2 cm de diâmetro, parede com $1-2,1 \mathrm{~mm}$ de espessura, faixa infranodal de tricomas ausentes; região mediana com formato cilíndrico. Nó proeminente, negro. Folha do colmo com bainha 13,2-14,7 × 2,4-2,9 cm, face adaxial e face abaxial com tricomas estrigosos; fímbrias $5-7 \mathrm{~mm}$, eretas a sinuosas, enroladas no ápice, amareladas a avermelhadas; lígula interna com 0,2-0,4 mm. Complemento de ramo com 3-87 ramos, estes com 16,7-152 cm compr., 2,7-4,8 de diâmetro, ramos de segunda ordem ausentes. Folhas dos ramos verdes 8-27 por ramo; bainha 3,4-5 $\mathrm{cm} \times 4-5,3 \mathrm{~mm}$, glabra ou glabrescente, margem sobreposta ciliada; fímbrias 1-2,1 mm compr.; retas a sinuosas, geralmente enroladas no ápice, amareladas a avermelhadas; lígula externa 0,2-0,3 mm compr.; lígula interna 0,3-0,4 mm compr.; pseudopecíolo 3-6 mm, esverdeado a castanho; lâmina 6,6-24,9 × 2,2-4,7 cm, lanceolada, base simétrica à assimétrica, ápice acuminado, margens serreadas, face adaxial glabra, face abaxial glabra ou glabrescente. Inflorescência racemosa, pectinada, $7 \mathrm{~cm}$ compr., raque velutina a tomentosa, bráctea estéril na base do racemo ausente, ca. 26 espiguetas. Espiguetas 11-12,5 × 1,5 mm, aos pares, às vezes solitárias, pares com duas espiguetas férteis ou uma fértil e outra rudimentar, 1-flora, pedicelo 0.5-1 mm compr., velutino na face adaxial. Glumas
2, desiguais. Gluma I 2-2,5 × 1-1,5 mm, 1-nervada, pubérula, nervura central escabra, margens ciliadas. Gluma II 4-4,5 × 2,5-3 mm, mucronada, 8-9-nervada, pubérula, nervura central escabra, margens ciliadas em direção ao ápice, manchas escuras adaxialmente. Lema 8-10 × 4-5 mm, 10-13 nervado, pubérulo, margens apicais ciliadas, uma das margens ciliada desde a base, manchas escuras adaxialmente. Pálea 9.5-11 × 3-5 mm, 8-nervada, pubérula, margens apicais ciliadas, nervuras centrais constituindo uma quilha, quilha ciliada em direção ao ápice, manchas escuras adaxialmente. Extensão da ráquila ca. 9-10,5 mm compr. Lodículas, Androceu, Gineceu e Cariopse não vistos.

Material examinado: BRASIL. Minas Gerais: Viçosa, Fazenda Bom Sucesso, Mata do Sr. Nico, 27-VIII-2014, D.F. Parma \& R.V. Silva 39, veg., (VIC). Idem, 12-IX-2014, D.F. Parma \& C.A. Costa 43, fl., (VIC). Idem, 12-IX-2014, D.F. Parma \& C.A. Costa 44, veg., (VIC). Idem, 10-X-2014, D.F. Parma \& C.A. Costa 52, veg., (VIC). Idem, 10-X-2014, D.F. Parma \& C.A. Costa 55, veg., (VIC). Estação de Pesquisa, Treinamento e Educação Ambiental (EPTEA), Mata do Paraíso, Trilha dos Gigantes, 2-V-2011, Santos-Gonçalves et al. 633, veg., (VIC).

Material adicional: BRASIL. MinAs GERAIS: Marliéria, Parque Estadual do Rio Doce, Estrada Cava GrandePonte Queimada, 21-XII-1999, Santos-Gonçalves et al. 319, veg., (VIC). Trilha da Garapa Torta, 20-IX-1999, Santos-Gonçalves et al. 197, veg., (VIC). Trilha do Aníbal, 19-V-1999, Santos-Gonçalves et al. 126, veg., (VIC). Idem, 26-VII-1999, SantosGonçalves et al. 174, veg., (VIC).

Merostachys sp. morfoespécie 1 se assemelha a M. annulifera por apresentar nós do colmo e dos ramos proeminentes, em formato anelar. Difere, no entanto, por apresentar bainha da folha do colmo e entrenó lanosos, enquanto $M$. annulifera possui bainha da folha do colmo e entrenó escabros. Merostachys sp. morfoespécie 1 é referida por Vinícius-Silva et al. (in prep.) como Merostachys sp. morfoespécie 1.

Distribuição: Merostachys sp. morfoespécie 1 ocorre no Leste e Sudeste Minas Gerais, onde é encontrada em sub-bosque e borda de vegetação caracterizada por Veloso et al. (1991) como Floresta Atlântica Estacional Semidecidual Montana e Floresta Atlântica Estacional Semidecidual Submontana.

Conservação: esse táxon ainda é desconhecido, pois não encontramos dados os suficientes para classificá-lo 
em alguma espécie já descrita. Assim, não há a possibilidade de se obter informações referentes à sua conservação.

\section{Merostachys sp. morfoespécie 2}

Figuras 1h, $2 \mathrm{~h}$

Planta arborescente. Colmo 12-15 m compr. Entrenó 17-53,6 cm compr., 1,8-2,5 cm de diâmetro, parede com 0,8-3 mm de espessura, verde-amarelado sem estrias, fosco, escabro, faixa infranodal de tricomas velutinos 1,4-5,6 mm compr., região mediana triangular, não cilíndrico; lúmen amplo, não preenchido por medula. Nó não proeminente, castanho. Folha do colmo 21-47 cm compr.; bainha 16,3-32,4 × 5,5-13 cm, face adaxial glabra, brilhante, face abaxial pubescente a serícea, às vezes glabrescente, margem sobreposta ciliada em direção ao ápice; lígula interna 0,4-2,8 mm compr., membranácea, pubescente, ápice ciliado; fímbrias não fusionadas, 2,5-24 mm compr., retas a sinuosas, geralmente enroladas no ápice, amarelada a castanha na base e prateadas em direção ao ápice; lâmina 4,5-15 × 0,42-1 cm, margens escabras em direção ao ápice, face adaxial escabra a híspida, às vezes esparsamente hirsuta, face abaxial pubescente a híspida, às vezes esparsamente hirsuta, ápice escabro. Complemento de ramo com 6-40 ramos, $12,5-165 \mathrm{~cm}$ compr.; 1,6-3 de diâmetro, ramos de segunda ordem presentes, 12,5-24 cm compr.; nós não proeminentes, castanhos a enegrecidos. Folha dos ramos 6-15 por ramo; bainha 1,5-7,5 $\mathrm{cm} \times 2,14-8,28 \mathrm{~mm}$, pubescente a tomentosa em direção ao ápice, às vezes glabra, margens apicais ciliadas, margem sobreposta ciliada; aurículas ausentes; lígula externa $0,15-0,5 \mathrm{~mm}$ compr., ápice ciliado; lígula interna $0,2-0,8 \mathrm{~cm}$ compr., membranácea, glabra a pubescente; fímbrias não fusionadas, 2,8-24,61 $\mathrm{mm}$ compr., retas a sinuosas, geralmente enroladas no ápice, prateadas; pseudopecíolo 1,2-4,5 mm compr., castanho claro, reto a retorcido, pubescente a tomentoso, às vezes híspido na face adaxial; lâmina 5-24,5 × 1,5-3,7 cm, lanceolada, base assimétrica, ápice acuminado, margens escabras, face adaxial com 3-5 nervuras marginais escabras, região marginal oposta com uma faixa de diminutos tricomas estrigosos em direção ao ápice, glabro no restante, face abaxial coberta por diminutos tricomas estrigosos, principalmente, próximo à estria discolor. Inflorescência não vista.

Material examinado: BRASIL. Minas Gerais: Viçosa, Palmital, 12-III-2012, A. Paz 4, veg., (VIC). Idem, 12-III-2012, A. Paz 5, veg., (VIC). Idem, 12-III-2012, A. Paz 6, veg., (VIC).
Material adicional: BRASIL. MinAS GERAIS: Marliéria, Parque Estadual do Rio Doce, Trilha da Lagoa do Meio, 21-IX-1999, Santos-Gonçalves et al. 201, veg., (VIC). Trilha da Lagoa Preta, 20-V-1999, SantosGonçalves et al. 137, veg., (VIC). Idem, 22-VI-1999, Santos-Gonçalves et al. 154, veg., (VIC).

Merostachys sp. morfoespécie 2 é referida por Vinícius-Silva (2015) como Merostachys sp. morfoespécie 5. Essa distingue-se das demais espécies aqui descritas por apresentar entrenó do mediocolmo em formato triangular (em seção transversal) e bainha da folha dos ramos com tricomas híspidos.

Distribuição: Merostachys sp. morfoespécie 2 é registrada apenas para Minas Gerais, onde ocorre em sua porção Sudeste em regiões caracterizadas por Veloso et al. (1991) como Floresta Atlântica Estacional Semidecidual Montana e Floresta Atlântica Estacional Semidecidual Submontana.

Conservação: esse táxon ainda é desconhecido, pois não encontramos dados os suficientes para classificálo em alguma espécie já descrita. Assim, não há a possibilidade de se obter informações referentes à sua conservação.

\section{Merostachys sp. morfoespécie 3}

Figuras 1i, 2i

Hábito não visto. Entrenó comp. não visto, verde-amarelado com estrias, fosco, híspido, coberto por tricomas, 0,6-1,0 cm de diâmetro, parede com 1-4 mm de espessura, faixa infranodal de tricomas, 2-3 mm; região mediana com formato cilíndrico. Nó não proeminente, castanho. Folha do colmo não vista. Complemento de ramo com 27-51 ramos, estes com 21-48 cm comp., 1,6-3 de diâmetro, ramos de segunda ordem ausentes. Folhas dos ramos verdes 7-10 por ramo; bainha 5,3-8,4 $\mathrm{cm} \times 5-9 \mathrm{~mm}$, glabra ou glabrescente, margem sobreposta ciliada; lígula externa 0,12-0,36 mm compr., ápice ciliado; lígula interna 0,1-2,4 mm compr., membranácea, pubescente, ápice ciliado; pseudopecíolo 8-12 mm, esverdeado a castanho na face adaxial. Inflorescência racemosa, pectinada, 7-14 cm compr., raque velutina a tomentosa, bráctea estéril na base do racemo ausente, ca. 36 espiguetas. Espiguetas 11-15,1 × 1,5 mm, solitárias, 1-flora, pedicelo 0,5-1 mm compr., velutino. Gluma I 2,5-3,5 × 1-1.5 mm, 1-nervada, pubérula, nervura central escabra, margens ciliadas. Gluma II não vista. Lema 11-17 × 4-5 mm, 10-13 nervado, pubérulo, margens apicais ciliadas, uma das margens 
ciliada desde a base, manchas escuras adaxialmente. Pálea 9,5-11 × 3-5 mm, 8-nervada, pubérula, margens apicais ciliadas, nervuras centrais constituindo uma quilha, quilha ciliada em direção ao ápice, manchas escuras adaxialmente. Extensão da ráquila ca. 9-11,5 mm compr. Lodículas, Androceu, Gineceu e Cariopse não vistos.

Material examinado: BRASIL. MinAs Gerais: Viçosa, Universidade Federal de Viçosa, 12-III-1999, $R$. Ribon, fl., (VIC). Sem localidade, 30-V-1930, Y. Mexia 4770, fl., (VIC).

Material adicional: BRASIL. MinAs GeraIs: Araponga, Parque Estadual da Serra do Brigadeiro, Trilha da Toca da Onça, 4-XII-2013, E. M. Pianissola 20, veg., (VIC). Trilha do Carvão, 6-VII-2013, M.M. Picanço \& E.P. Machado 9, veg., (VIC). Idem, 7- VII-2013, M.M. Picanço \& E.P. Machado 16, veg., (VIC). Idem, 6-VIII-2013, M.M. Picanço \& E.P. Machado 10, veg., (VIC). Idem, 6-VIII-2013, M.M. Picanço \& E.P. Machado 11, veg., (VIC). Idem, 9-IX-2013, M.M. Picanço, D.F. Parma \& E.P. Machado 25, veg., (VIC). Trilha do Panelão dos Muriquis, 21-X-2013, E.M. Pianissola, A.L. Fontes \& M.N. Moura 2, veg., (VIC).

Merostachys sp. morfoespécie 3 é referida por Vinícius-Silva (2015) como Merostachys sp. morfoespécie 1. Essa distingue-se das demais espécies do gênero ocorrentes em Viçosa por apresentar bainha da folha dos ramos glabra e faixa infranodal de tricomas velutinos ausente.

Distribuição: a espécie é registrada apenas para Minas Gerais, onde ocorre em sua região Sudeste em regiões caracterizada por Veloso et al. (1991) como Floresta Atlântica Estacional Semidecidual Montana e Floresta Atlântica Estacional Semidecidual Submontana.

Conservação: essa espécie ainda é desconhecida, assim não há possibilidade de inferir dados referentes à sua conservação.

\section{Considerações finais}

O presente estudo evidencia uma riqueza considerável para os fragmentos florestais estudados. Além disso, amplia a área de ocorrência de Merostachys tatianae, espécie até agora conhecida como ocorrente somente no Parque Estadual do Rio Doce em Minas Gerais; $M$. skvortzovii é aqui registrada pela primeira vez como ocorrente no estado de Minas Gerais. Das espécies levantadas, somente Chusquea tenuiglumis se encontra na categoria vulnerável. Merostachys fischeriana e M. skvortzovii apresentam ampla distribuição no país e $M$. tatianae é reconhecida em outra localidade do Estado de Minas Gerais. Em virtude disso, nossos resultados comprovam a importância da conservação da biodiversidade no município de Viçosa.

\section{Agradecimentos}

Ao Conselho Nacional de Desenvolvimento Científico e Tecnológico(CNPq 563545/2010-0-Reflora) e aos proprietários das áreas amostradas que permitiram a realização das coletas.

\section{Literatura citada}

Coelho D.J.S., Souza, A.L. \& Oliveira, C.M.L. 2005. Levantamento da cobertura florestal natural da microrregião de Viçosa, MG, utilizando-se imagens de Landsat. Revista Árvore 29: 17-24.

Ferreira, F.M., Costa, A.F. \& Forzza, R.C. 2009. Bambusoideae (Poaceae) no Parque Estadual de Ibitipoca, Minas Gerais, Brasil. Boletim de Botânica da Universidade de São Paulo 27: 203-218.

Filgueiras, T.S. \& Santos-Gonçalves, A.P. 2004. Checklist of the basal grasses and bamboos in Brazil (Poaceae). The Journal of the American Bamboo Society 18: 7-18.

Filgueiras, T.S., Brochado, A.L., Nogueira, P.E. \& Guala Ii, G.F. 1994. Caminhamento - um método expedito para levantamentos florísticos qualitativos. Caderno de Geociências, 2: 39-43.

GPWG. 2001. Phylogeny and subfamilial classification of the grasses (Poaceae). Annals of the Missouri Botanical Garden 88: 373-457

IUCN. 2001. IUCN Red list categories and criteria: version 3.1 IUCN Species Survival Commission, Gland, Switzerland and Cambridge, United Kingdom.

Janzen, D. 1976. Why bamboos wait so long to flower. Annual Review of Ecology and Systematics 7: 374-391.

Judziewicz, E.J., Clark, L.G., Londoño, X. \& Stern, M.J. 1999. American Bamboos. Washington: Smithsonian Institution Press.

Mamede, M.C.H., Souza, V.C., Prado, J., Barros, F., Wanderley, M.G.L. \& Rando, J.G. (orgs.). 2007. Livro vermelho das espécies vegetais ameaçadas do Estado de São Paulo. Instituto de Botânica, São Paulo.

McClure, F.A. 1966. The bamboos: a fresh perspective. Cambridge: Harvard University Press.

Mota, A.C. 2013. Sistemática de Chusquea subgênero Rettbergia (Bambusoideae, Poaceae). Tese de Doutorado, Universidade Estadual de Feira de Santana, Feira de Santana.

Flora do Brasil 2020 (em construção). 2016. Poaceae. Jardim Botânico do Rio de Janeiro. Disponível em http:// floradobrasil.jbrj.gov.br/reflora/floradobrasil/FB102232 (acesso em 14-VI-2016). 
Radford, L.E., Dickison, W.C., Massey, I.R. \& Bek, C. 1974. Vascular Plant Systematics. Harper \& Row, New York.

Renvoize, S.A. 1984. The grass of Bahia. Royal Botanical Gardens, Kew.

Santos-Gonçalves, A.P., Carvalho-Okano, R.M., Vieira, M.F. \& Filgueiras, T.S. 2006. Bambus (Bambusoideae: Poaceae) do Parque Estadual do Rio Doce, Minas Gerais: Florística e Taxonomia. In: Anais do I Seminário Nacional do Bambu: Estruturação da Rede de Pesquisa e Desenvolvimento, 2 ed., Brasília, pp. 43-48.

Schmidt, R., Longhi-Wagner, M.H. 2009. A tribo Bambuseae (Poaceae, Bambusoideae) no Rio Grande do Sul. Revista Brasileira de Biociências, 7: 71-128.

Seifriz, W. 1950. Gregarious flowering in Chusquea. Nature 65: 635-636.

Shirasuna, R.T. 2015. Merostachys in Lista de Espécies da Flora do Brasil. Jardim Botânico do Rio de Janeiro. Disponível em http://floradobrasil. jbrj.gov.br/jabot/floradobrasil/FB13328 (acesso em 11- XII- 2015).

Shirasuna, R.T., Oliveira, R.P. \& Mota, A.C. 2015. Chusquea in Lista de Espécies da Flora do Brasil. Jardim Botânico do Rio de Janeiro. Disponível em http:// floradobrasil.jbrj.gov.br/jabot/floradobrasil/FB13120 (acesso em 11- XII- 2015).

Silva, A.F., Oliveira, R.V., Santos, N.R.L. \& Paula, A. 2003. Composição florística e grupos ecológicos das espécies de um trecho de floresta semidecídua submontana da Fazenda São Geraldo, Viçosa-MG. Revista Árvore 3: 311-319.

Silva, A.P. 2016. Bambusoideae (Poaceae) no Parque Estadual da Serra do Brigadeiro, Minas Gerais, Brasil. Dissertação de Mestrado, Universidade Federal de Viçosa, Viçosa.
Soderstrom, T.R. 1981. Observations on a fire-adapted bamboo of the Brazilian cerrado: Actinocladum verticilatum (Poaceae: Bambusoideae). American Journal of Botany, 68: 1200-1211.

Soderstrom, T.R. \& Young, S.M. 1983.A guide to collecting bamboos. Annals of the Missouri Botanical Garden 70: 128-136.

Soderstrom, T.R., Judiziewicz, E.J. \& Clark, L.G. 1988. Distribution patterns of Neotropical Bamboos. In: P.E. Vanzolini, \& R.E. Heyer (eds.). Proceedings of a Workshop on Neotropical Distribution Patterns. Rio de Janeiro: Academia Brasileira de Ciências, pp. 121-157.

Sungkaew, S., Stapleton, C.M.A., Salamin, N. \& Hodkinson, T.R. 2009. Non-monophyly of the woody bamboos (Bambusoideae; Poaceae): a multi-gene region phylogenetic analysis of Bambusoideae s.s. Journal of Plant Research 122: 95-108.

Thiers, B. 2016 [continuously updated]. Index Herbariorum:A global directory of public herbaria and associated staff. New York Botanical Garden's Virtual Herbarium. Disponível em: http://sweetgum.nybg.org/ ih/ (acesso em 08-IV-2016).

Veloso, H.P., Rangel-Filho, A.L.R. \& Lima, J.C.A. 1991. Classificação da vegetação brasileira adaptada a um sistema universal. Rio de Janeiro, Instituto Brasileiro de Geografica e Estatística.

Viana, P.L. 2005. Contribuição para o conhecimento das Poaceae no Parque Estadual do Rio Preto, Minas Gerais, Brasil. Dissertação de Mestrado, Universidade Federal de Minas Gerais, Belo Horizonte.

Vinícius-Silva, R. 2015. Merostachys Spreng. (Poaceae: Bambusoideae: Bambuseae: Arthrostylidiinae) no leste do estado de Minas Gerais, Brasil. Dissertação de Mestrado, Universidade Federal de Viçosa, Viçosa.

Zhang, W. \& Clark, L.G. 2000. Phylogeny and classification of the Bambusoideae (Poaceae). In: S.W.L. Jacobs \& J.E. Everett (eds.). Grasses: systematics and evolution. CSIRO, Collingwood. pp. 35-42. 